\title{
Estimation of field irrigation water demand based on lumped kinematic wave model considering soil moisture balance
}

\section{$\operatorname{AUTHOR}(S):$}

HORI, Tomoharu; SUGIMOTO, Takeyuki;

NAKAYAMA, Masayuki; ICHIKAWA, Yutaka; SHIIBA, Michiharu

\section{CITATION:}

HORI, Tomoharu ...[et al]. Estimation of field irrigation water demand based on lumped kinematic wave model considering soil moisture balance. Physics and Chemistry of the Earth, Parts A/B/C 2008, 33(5): 376-381

\section{ISSUE DATE:}

2008

URL:

http://hdl.handle.net/2433/93460

\section{RIGHT:}

Copyright (C) 2008 Published by Elsevier Ltd.; This is not the published version. Please cite only the published version.; この論文は出版社版で ありません。引用の際には出版社版をご確認ご利用ください。 


\title{
Estimation of Field Irrigation Water Demand based on Lamped Kinematic Wave Model Considering Soil Moisture Balance
}

\author{
Tomoharu Hori ${ }^{1}$, Takeyuki Sugimoto ${ }^{2}$, Masayuki Nakayama ${ }^{2}$, Yutaka Ichikawa ${ }^{1}$ and \\ Michiharu Shiiba ${ }^{1}$ \\ ${ }^{1}$ Graduate School of Global Environmental Studies, Kyoto University, Yoshida-Honmachi, Sakyo-ku, Kyoto 606-8501, \\ Japan \\ ${ }^{2}$ Graduate School of Engineering, Kyoto University, Yoshida-Honmachi, Sakyo-ku, Kyoto 606-8501, Japan
}

\begin{abstract}
An estimation model of farm field irrigation water demand is developed. The model is based on the lamped kinemtic wave model considering soil water balance. The lamped model approach reduces the computational load in rainfall-runoff analysis and allows application to large river basins. Evapotranspiration is estimated on hourly basis by the improvement of FAO's method. Not only water volume necessary for farm field irrigation but also the number of the water charge and its interval can be estimated by the combined use of the lamped runoff model and the hourly evapotranspiration model.
\end{abstract}

\section{INTRODUCTION}

One of the most important issues related to water resources is agricultural water use. Irrigated water demand in the world will keep increasing in order to make agricultural products to provide food to increasing world population. It is pointed out that water which can be used for agriculture will be constraints to the society in several areas in the world. Moreover the climate change brought by the global warming enforces spatial and temporal mal-distribution of water resources in the world. Also in Japan, severe drought occurs in recent years. The damage brought by the drought occurred in 1994 was widely spread all over Japan.

Agricultural products are one of the most vulnerable ones and directly affected by water shortage. In order to cope with drought and with water shortage, comprehensive water management and basin management are indispensable. To do that from agricultural point of view, it is necessary to know quantitatively:

- how much water is actual necessary for irrigation and how large the water deficit is,

- when the available water is smaller than agricultural demand, how much the damage is, and

- how much volume and how long duration of water deficit cause the unrecoverable effect on crop plants.

However even in Japan, where various kinds of data related to water resources and hydrologic cycles are widely observed and collected, water use data related to agricultural production is not sufficiently arranged. Ministry of Land, Infrastructure and Transportation of Japanese government publishes every year water withdrawal for agricultural purposes, but they are not actually observed ones but estimations calculated from irrigation area and unit requirement. The volumes of water use right is set to each river and withdrawal for irrigation purposes are done based on the right. But these values are maximum discharges that agricultural sections can withdraw from river systems and cannot be exact estimation of actual water demand for agricultural products. Moreover, water consumption depends on water charging way to farmlands.

In order to grasp quantitatively the relation between water volume and agricultural productivity, we will try to develop the basic part of the quantitative estimation model of farm field irrigation water demand taking hill slope runoff mechanism and soil water balance. The model is based on lamped kinematic wave approach and soil water balance considering field capacity. FAO's method is improved to simulate hourly evapotranspiration from hill slopes and farm fields. Combined use of lamped kinematic wave model considering field capacity and improved evapotranspiration model enables us to simulate water balance in farm field on hourly basis, which can be used to analyze the irrigation management and the effect of water deficit on crop plants.

\section{LAMPED KINEMATIC WAVE MODEL CONSIDERING FIELD CAPACITY}

When the field irrigation water demand is considered in a basin-wide scale, it is important to grasp temporal and spatial water movement, and distribution of soil moisture. Distributed runoff modeling is essential to meet this need. It requires, however, considerable computational burden and brings us difficulty in treating a basin-wide 
scale. From this viewpoint, lamped kinematic wave model approach is still promising to simulate runoff phenomena. Kinematic wave approach has been mainly used to compute flood runoff in mountainous basins. Ichikawa et. al. (2001) derived lumped kinematic wave equation sets considering field capacity. The lamping method is characterized by that storage-outflow relation is derived from the flow dynamic equations with reference to the spatial distribution of water and topographic features of a basin. Since they adopt the kinematic wave equation with field capacity, the lumped model can be used to compute soil moisture change as well as flood runoff. Therefore in this study, we use the lamped kinematic wave model by Ichikawa et. al. (2001) to know the water deficit in farm fields.

The lamped model adopts the following kinematic wave equation proposed by Shiiba et. al. (1999) to incorporate the effect of field capacity:

$$
h(x)=u\left(h_{f}\right)=\left\{\begin{array}{c}
h_{f}+h_{c}\left(1-\left(\frac{d-h_{f}}{d}\right)^{N}\right)^{1 / N} \quad\left(0 \leq h_{f}<d\right) \\
h_{f}+h_{c} \quad\left(h_{f} \geq d\right)
\end{array}\right.
$$

where $h$ denotes water depth [m], $h_{f}$ : free water depth [m], $h_{c}$ : equivalent water depth to field capacity [m], $d$ : pore depth $[\mathrm{m}], N$ : parameter $(>1)$. The free water depth, $h_{f}$, follows the surface-subsurface flow dynamic equation:

$$
q=g\left(h_{f}\right)=\left\{\begin{array}{c}
a h_{f} \quad\left(0 \leq h_{f}<d\right) \\
\alpha\left(h_{f}-d\right)^{m}+a h_{f} \quad\left(h_{f} \geq d\right)
\end{array}\right.
$$

where $q$ is flow discharge per unit width [ $\left.\mathrm{m}^{2} / \mathrm{s}\right], \alpha=\sqrt{\sin \theta} / n, a=k \sin \theta / \gamma, \theta$ : slope gradient, $n$ : Manning's roughness coefficient $\left[\mathrm{m}^{-1 / 3} / \mathrm{s}\right], k$ : hydraulic conductivity $[\mathrm{m} / \mathrm{s}], \quad \gamma:$ porosity of surface soil layer.

The lamping framework of equations (1) and (2) by Ichikawa et. al. (2001) is based on the basic idea that

1) a target area is modeled as a set of small rectangular slope elements,

2) spatial distribution of discharge and cross-sectional area of flow in the area is approximated by that in steady state conditions, and

3) the lamped relationship between discharge and cross-sectional area is derived by integrating the cross-sectional area spatially over the target area.

The generalized relation between the discharge per unit width $q(x, t)$ and water depth $h(x, t)$ is expressed by

$$
q(x, t)=g(h(x, t))
$$

where $x$ denotes the distance from the up most point of a slope element and $t$ denotes the time. The inverse expression of equation (3) is

$$
h(x, t)=f(q(x, t)) .
$$

If the rainfall-runoff system is steady, the storage volume, $s$, of the slope element is given by

$$
s=\bar{w} \int_{0}^{L} h(x) d x
$$

where $\bar{w}$ and $L$ denote the slope width and length respectively. By the assumption of steady state, discharge in a slope element $Q(x)$ and discharge per unit width $q(t)$ can be expressed in terms of steady rainfall intensity $\bar{r}$ :

$$
\begin{aligned}
& Q(x)=\bar{r} U+\overline{r w} x \\
& q(x)=Q(x) / \bar{w}=\bar{r} U / \bar{w}+\bar{r} x
\end{aligned}
$$

where $U$ is the total area of slope elements located upper part of the specified one. Noting that $f(\cdot)$ in eq. (4) cannot always be given explicitly, the integration should be done in terms of $q$ instead of $x$, namely,

$$
\begin{aligned}
s & =\bar{w} / \bar{r} \int_{q(0)}^{q(L)} f(q) d q \\
& =\bar{w} / \bar{r}[F(q(L))-F(q(0))]
\end{aligned}
$$

where $d F / d q=f$. The function $F(q(x))$ is given by

$$
F(q(x))=q(x) h(x)-\int_{0}^{h(x)} g(h) d h .
$$


The procedure to compute the discharge - flow area relation based on the above equations can be summarized as follows:

1) assuming the value of $\bar{r}$, compute $q(L)$ and $q(0)$ by eq. (9),

2) numerically compute $h_{f}(0)$ and $h_{f}(L)$, which are free water depths corresponding to $q(0)$ and $q(L)$ respectively, by eq. (2),

3) obtain $h(0)$ and $h(L)$ by eq. (1),

4) compute $F(q(0))$ and $F(q(L))$ using $h(0)$ and $h(L)$, and finally,

5) compute storage volume, $s$, of the specified slope element by eq. (8).

Performing the above mentioned procedure for all the slope elements in the target region, the total storage of the target area, $S$, is given by

$$
S=\sum_{i=1}^{N} s_{i}
$$

and outflow from the area, $O$,

$$
O=\bar{r} \sum_{i=1}^{N} A_{i}
$$

where $s_{i}$ and $A_{i}$ denote storage and area of slope element $i$ respectively and $N$ is the number of slope elements in the target region. Computation of $S-O$ pairs for various values of $\bar{r}$ gives the storage and outflow relation which varies with rainfall intensity. Then for unsteady rainfall in real case, storage and runoff can be simulated by the following ordinary differential equations,

$$
\left\{\begin{array}{l}
\frac{d S(t)}{d t}=A(r(t)-E(t))-O(t) \\
O(t)=g(S(t))
\end{array}\right.
$$

where $E(t)$ denotes evapotranspiration at time $t$ and $A$ the area of target region.

\section{ESTIMATION OF HOURLY EVAPOTRANSPIRATION}

Evapotranspiration is one of the most important factors in estimating agricultural water demand. Its estimation is usually done in daily basis when long term water balance in a basin is of interest. In order to incorporate the effects of short but relatively severe rainfall, which often appears in midsummer in Japan, the hourly analysis is eligible. From this viewpoint, hourly simulation framework of storage and runoff has been introduced in section 2. Therefore in this section, hourly estimation of evapotranspiration is discussed.

There are several methods to estimate evapotranspiration. Among them Penman-Monteith method has the advantage that it can take the effect of aerodynamic and vegetation resistance into acount and is widely used to compute potential evapotranspiration. Penman-Monteith equation is expressed as

$$
l E=\frac{\Delta\left(R_{\mathrm{n}}-G\right)-c_{\mathrm{p}} \rho\left(e^{*}-e\right) / r_{\mathrm{A}}}{\Delta+\gamma\left(1+r_{\mathrm{C}} / r_{\mathrm{A}}\right)}
$$

where $l$ denotes the latent heat of water evaporation $\left[\mathrm{J} \mathrm{kg}^{-1}\right], E$ : vapor flux $\left[\mathrm{kg} \mathrm{m}^{-2} \mathrm{~s}^{-1}\right], G$ : ground heat flux $\left[\mathrm{W} / \mathrm{m}^{2}\right], c_{\mathrm{p}}$ : isopiestic specific heat of atmosphere $\left[\mathrm{J} \mathrm{kg}^{-1} \mathrm{~K}^{-1}\right], \rho$ : density of the air $\left[\mathrm{kgm}^{-3}\right], e$ : vapor pressure $[\mathrm{hPa}], e^{*}:$ saturated vapor pressure $[\mathrm{hPa}], r_{\mathrm{A}}:$ aerodynamic resistance, $r_{\mathrm{C}}$ : vegetation resistance. Net radiation $R_{\mathrm{n}}\left[\mathrm{Wm}^{-2}\right]$ is given by

$$
R_{\mathrm{n}}=(1-\lambda) S^{\downarrow}-\alpha\left(\sigma T_{\mathrm{s}}^{4}-L^{\downarrow}\right)
$$

where $\lambda$ is albedo, $\alpha$ : injection rate, $S^{\downarrow}$ : downward solar radiation $\left[\mathrm{Wm}^{-2}\right], L^{\downarrow}$ : downward long-wave radiation $\left[\mathrm{Wm}^{-2}\right], \sigma:$ Stephan-Boltzmann constant and $T_{s}$ : land surface temperature $[\mathrm{K}]$. The variable $\Delta$ denotes the rate of saturated vapor pressure change with the temperature and $\gamma$ is given by 


$$
\gamma \equiv \frac{c_{\mathrm{p}} P}{\varepsilon l}
$$

where $P$ is atmospheric pressure and $\varepsilon$ is molecular mass ratio of water vapor and atmosphere.

Substituting hourly net radiation into eq. (13), we can obtain hourly potential evapotranspiration. In many cases, however, hourly net radiation is not available. FAO introduced the way to compute daily net radiation using duration of bright sunshine, air temperature and moisture content. In this study, we introduce the way to estimate hourly net radiation making improvements on FAO's daily estimation.

The solar radiation onto the horizontal surface at the top of atmosphere, $S_{0}^{\downarrow}{ }_{\min }\left[\mathrm{MJ} \mathrm{m}^{-2} \mathrm{~min}^{-1}\right]$, is given by

$$
S_{0 \text { min }}^{\downarrow}=G_{\mathrm{sc}} d_{\mathrm{r}} \sin h=G_{\mathrm{sc}} d_{\mathrm{r}}(\sin \varphi \sin \delta+\cos \varphi \cos \delta \cos \omega)
$$

where $G_{\mathrm{sc}}$ and $\varphi$ denote solar constant and latitude, respectively. Hour angle $\delta$ is given by

$$
\omega=\frac{2 \pi}{24} \times(t-12)
$$

where $t$ is the time [hour] in a day. The change effect on solar radiation caused by earth's elliptic orbit is expressed by $d_{\mathrm{r}}$ defined by

$$
d_{\mathrm{r}}=1+0.033 \cos \left(\frac{2 \pi}{365} J\right)
$$

where $J$ is the day of the year. Amplitude between the earth and the sun, $\delta$, is given by

$$
\delta=0.409 \sin \left(\frac{2 \pi}{365} J-1.39\right) \text {. }
$$

In this study, hourly solar radiation at time $t, S_{0 \text { hour }}^{\downarrow}$, is computed by integrating eq.(16) between thirty minutes before and after $t$, namely,

$$
\begin{aligned}
S_{0 \text { hour }}^{\downarrow} & =\frac{24 \cdot 60}{2 \pi} G_{\mathrm{sc}} d_{\mathrm{r}}\left[\left(\omega_{2}-\omega_{1}\right) \sin \varphi \sin \delta+\cos \varphi \cos \delta\left(\sin \omega_{2}-\sin \omega_{1}\right)\right] \\
\omega_{1} & =\omega-\frac{\pi}{24}=\frac{2 \pi}{24} \times(t-12)-\frac{\pi}{24}=\frac{(2 t-25) \pi}{24} \\
\omega_{2} & =\omega+\frac{\pi}{24}=\frac{2 \pi}{24} \times(t-12)+\frac{\pi}{24}=\frac{(2 t-23) \pi}{24}
\end{aligned}
$$

where $\omega_{1}$ and $\omega_{2}$ denote the hour angles at thirty minutes before and after $t$. Hourly solar radiation at land surface, $S_{\text {hour }}^{\downarrow}$, is given as follows by using $S_{0 \text { hour }}^{\downarrow}$ computed by eq. (20):

$$
S_{\text {hour }}^{\downarrow}=\left(a_{\mathrm{s}}+n_{\text {hour }} b_{\mathrm{s}}\right) S_{0 \text { hour }}^{\downarrow}
$$

The above equation is based on FAO's equation to compute daily solar radiation but it is extended to the hourly basis. The coefficients $a_{\mathrm{s}}$ and $b_{\mathrm{s}}$ expresses the effect of the weather such as cloud conditions. FAO recommends to use the values of $a_{\mathrm{s}}=0.25$ and $b_{\mathrm{s}}=0.50$ under the lack of data, which is adopted also in this study. The symbol $n_{\text {hour }}$ denotes the duration of bright sunshine per hour, which is actually observed by Japan Meteorological Agency.

Hourly net infrared radiation, $L_{\mathrm{n} \text { hour }}\left[\mathrm{MJm}^{-2} \mathrm{hour}^{-1}\right]$, can be computed by the following equation, where hourly atmospheric temperature is used instead of daily one in FAO's equation,

$$
L_{\text {n hour }}=\frac{\sigma T}{24}(0.34-0.14 \sqrt{e})\left(1.35 \frac{S_{\text {hour }}^{\downarrow}}{S_{0 \text { hour }}^{\downarrow}}-0.35\right) .
$$

Finally the hourly net radiation $R_{\mathrm{n} \text { hour }}$ can be simulated by

$$
R_{\mathrm{n} \text { hour }}=(1-\lambda) S_{\text {hour }}^{\downarrow}-L_{\mathrm{n} \text { hour }} .
$$

From the data of atmospheric temperature, relative humidity, barometric pressure and duration of bright sunshine on the hourly basis, which are observed by the Meteorological Agency and open to public in Japan. 


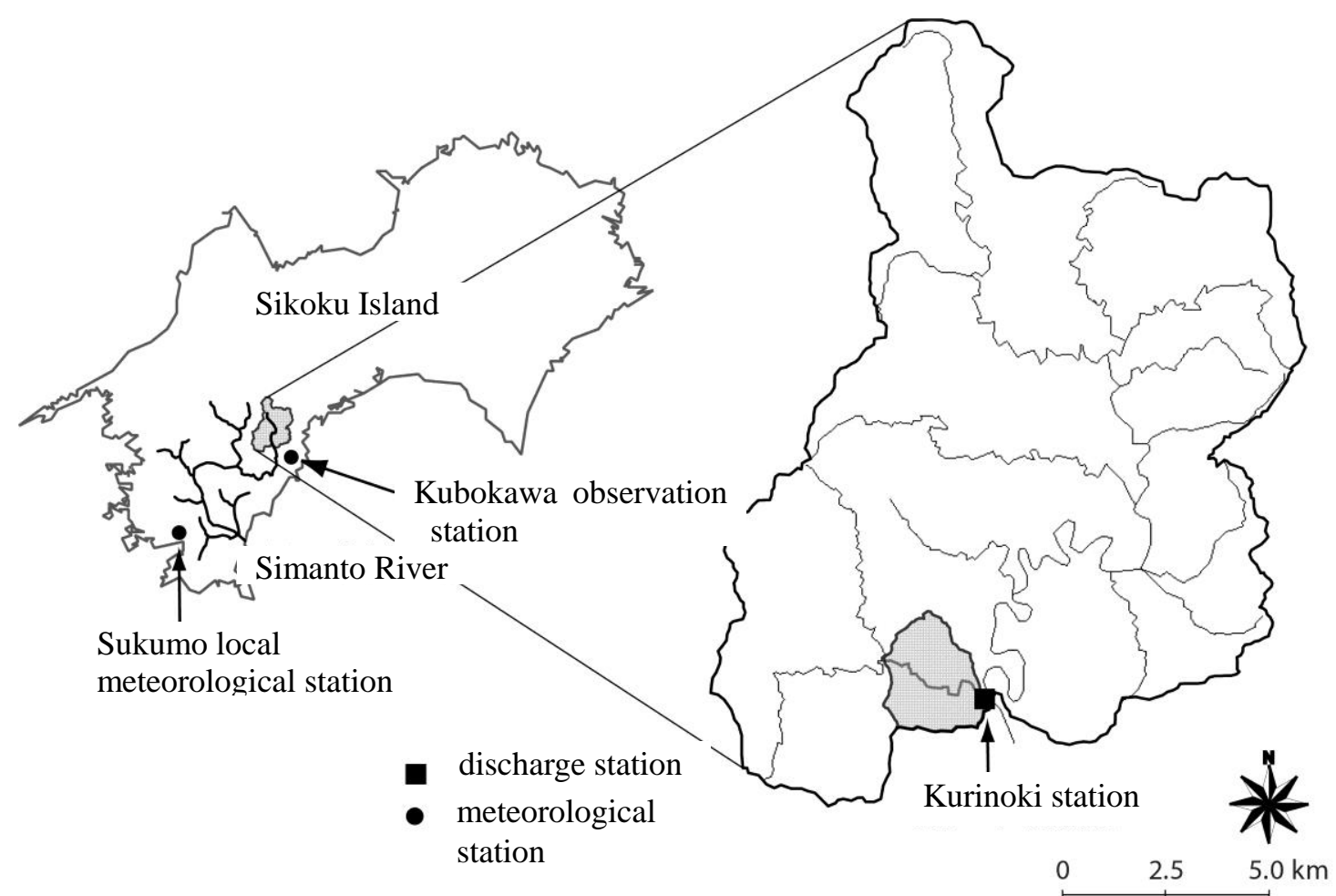

Figure 1 The Simanto River Basin (Case study area)

\section{A PRELIMINARY CASE STUDY}

The case study area is a part of Shimanto River Basin, which is located at southern west part of Shikoku Island (Fig. 1). The river has the main channel length of $196 \mathrm{~km}$ flowing through the basin with the area of 2,270 $\mathrm{km}^{2}$. It is characterized by its mild slope of $1 / 85$ at the upper reaches and $1 / 833$ at the lower. The study area is the sub-basin upper than Kurinoki observation station of the Ministry of Land, Infrastructure and Transportation. The area is divided into $23 \mathrm{sub}$ catchments based on the digital elevation model and the lamped kinematic wave model considering soil moisture balance described in section 2 is applied to each of the sub catchments. Flow discharges are observed by Kurinoki station, air pressure and relative humidity are observed by Kubokawa AMeDAS station, and atmospheric temperature, rainfall and duration of bright sunshine are observed by Sukumo local meteorological station.

Figure 2 shows the calculated and observed discharges from January 1 to December 31, 2002. The solid line in the figure denotes the simulated flow discharge and the dotted one denotes the observed. It can be seen that the simulated and observed discharges matches well during low flow time but that the simulated discharge tends to give larger values than the observations when large flow is observed. This is because calibration of runoff model has been done focusing on goodness of fit during low flow durations since we are to estimate farm field water demand based on the lack of soil moisture. The parameters determined by calibration are $n=0.6 \mathrm{~m}^{1 / 3} s$, $m=1.667, k=0.015 \mathrm{~m} / \mathrm{s}, \gamma=0.4, \gamma_{c}=0.1, D=1.0 \mathrm{~m}, N=6.0$.

Figure 3 illustrates the temporal change of water level stored in soil layer at the sub-catchment, which is shown by dark colored area in Figure 1. The depth of soil layer at the area is $30 \mathrm{~cm}$ and water height corresponding to field capacity is $10 \mathrm{~cm}$. It is generally said that the water plants use for their growing exists between field capacity and wilting point. In actual cases, the water demand depends on the sort of crop plants and their stage of growing. But here we adopt a very simple assumption that irrigation is performed based on the difference between the field capacity and water level in the soil layer. The irrigation rule based on this assumption is as follows:

1) farm area is irrigated from May to October, 


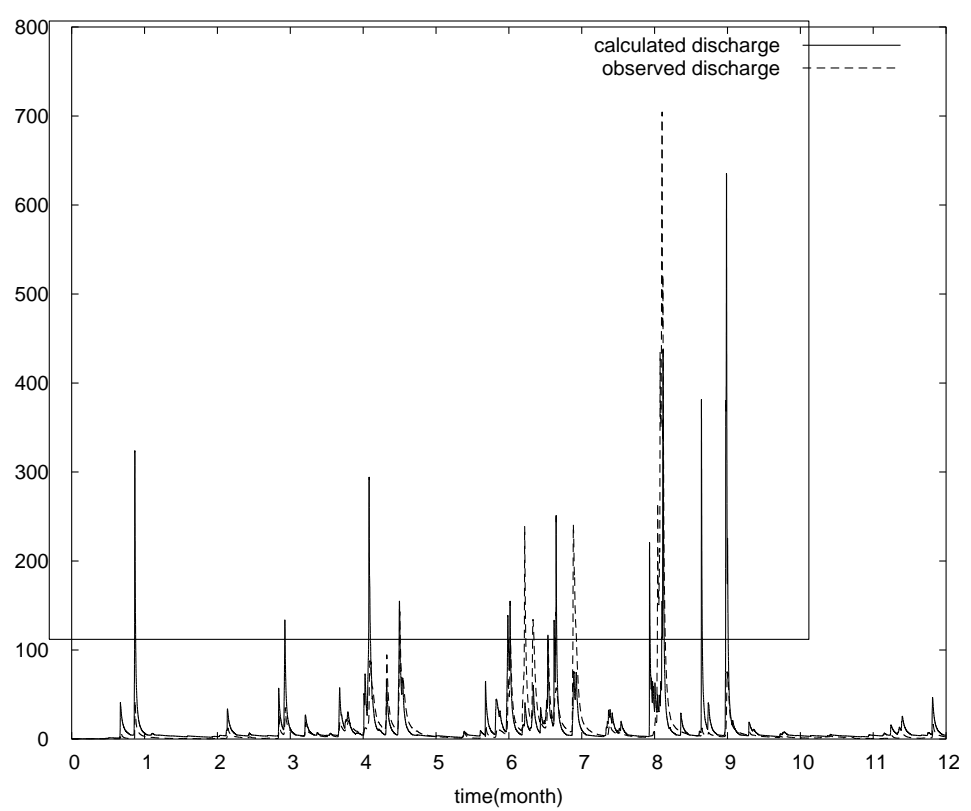

Figure 2 Computed and observed discharge at Kakinoki observation point.

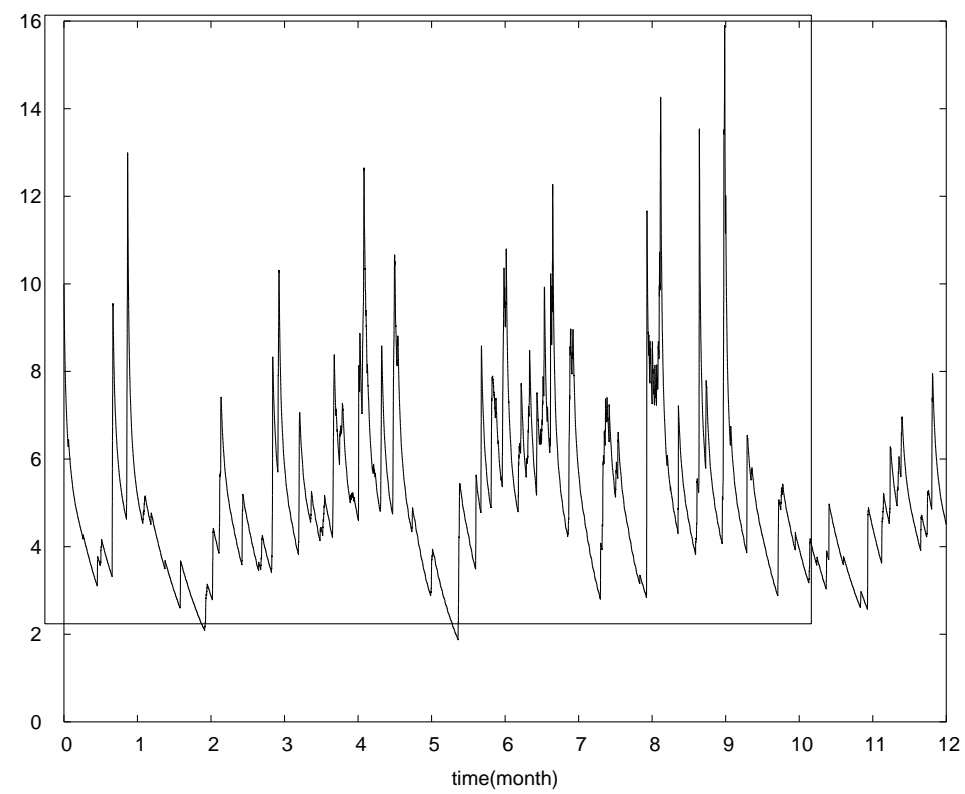

Figure 3 temporal change in water level in soil layer.

2) irrigated water is instantly infused at the moment when water height in soil layer comes down to $50 \%$ of the field capacity, and

3) water level in the soil layer comes to that corresponding to field capacity when irrigated.

The change of water storage in the irrigated case is shown in Fig. 3. The abrupt uprise in water level just after it comes down to $5 \mathrm{~cm}$ (50\% of field capacity) is brought by the irrigation and we can see that water pumping is necessary in every month. Pumping is performed 26 times in the irrigation term and the average interval is 6.92 days.

Water which is needed for farm field irrigation may vary with the way of charging. Therefore several irrigation simulations are performed based on the water levels recovered by water charge. Table 1 summarizes the results of simulations, in which the target water depth recovered by water charge is changed from $10 \mathrm{~cm}$ to $15 \mathrm{~cm}$. Since the field capacity level is $10 \mathrm{~cm}$ in the case study area, 11 to $15 \mathrm{~cm}$ recoveries exceed the field 
Table 1 Results for various irrigation scenarios

\begin{tabular}{|c|c|c|c|}
\hline $\begin{array}{c}\text { Target water height in soil } \\
\text { layer }(\mathrm{cm})\end{array}$ & $\begin{array}{c}\text { the number } \\
\text { of charging }\end{array}$ & $\begin{array}{c}\text { Average interval of charging } \\
(\text { day })\end{array}$ & $\begin{array}{c}\text { total irrigation volume } \\
\left(\mathrm{m}^{3}\right)\end{array}$ \\
\hline 10 & 26 & 6.92 & 469,703 \\
\hline \hline 11 & 26 & 6.92 & 563,643 \\
\hline 12 & 24 & 7.5 & 607,000 \\
\hline 13 & 23 & 7.83 & 664,810 \\
\hline 14 & 23 & 7.83 & 747,911 \\
\hline 15 & 23 & 7.83 & 831,012 \\
\hline
\end{tabular}

capacity. It can be seen from Table 1 that the number of recharge times decreases with the increase of target recharge level and that average interval increases. When the recharge target level is more than $13 \mathrm{~cm}$, the number of recharge times and the average interval do not change while the water volume increases. We should note that water charged into farm fields should be controlled according to the soil layer characteristics.

\section{CONCLUDING REMARKS}

In this study, we have developed an estimation model of farm field irrigation water demand. The model developed here is based on the lamped kinemtic wave model considering soil water balance. The lamped model approach reduces the computational load in rainfall-runoff analysis and allows application to large river basins. Evapotranspiration is estimated on houly basis by the improvement of FAO's method. Not only water volume necessary for farm field irrigation but also the number of the water charge and its interval can be estimated by the combined use of the lamped runoff model and the hourly evapotranspiration model.

On the contrary, the application has been done only in a relatively small sub-basin and the difference in crop plants has not been taken into account. We will incorporate the effect of the kind of crop plant and of their growing stages in near future. The agricultural water demand model based on the simulation of runoff and soil moisture balance as discussed here will be of great help when we consider water resources distribution to various purposes and effective control of irrigation.

\section{REFERENCES}

Allen, R.G., Pereira, L.S., Raes, D., and Smith, M. (1998). "Crop evapotranspiration - Guidelines for computing crop water requirements", FAO Irrigation and drainage, paper 56, http://www.fao.org/docrep/.

Ichikawa,Y., Murata, Y., and Shiiba M. (2001). "Lumping of Kinematic Wave Equation Considering Field Capacity”, Annuals, DPRI, Vol. 44 B-2, pp. 313-321 (in Japanese).

Ministry of Land, Infrastructure and Transportation (2005). "Water Resources in Japan, 2005" (in Japanese).

Shiiba M., Tachikawa, Y., Ichikawa, Y., Hori, T., and Tanaka, K. (1998). "Development of Slope Runoff Models which Consider Field Capacity and Pipe Flows", Annuals, DPRI, Vol. 41 B-2, pp. 229-236 (in Japanese). 